\title{
Socio-demographic Characteristics and Mode of Traumatic Thoraco-Lumbar Spine Injuries at a Referral Tertiary Care Hospital in Bangladesh
}

\author{
Md. Mizanur Rahman', Md. Mahfuzur Rahman², Md. Abdullah Yusuf ${ }^{3}$, AFM \\ Arshedi Sattar ${ }^{4}$, Md. Ayub Ali ${ }^{5}$, Md. Matiur Rahman ${ }^{6}$, Abu Bakar Siddique ${ }^{7}$ \\ ${ }^{1}$ Junior Consultant (Ortho-surgery), Upazila Health Complex, Gaforgaon, Mymensingh, Bangladesh; ${ }^{2}$ Assistant Professor, \\ Department of Neurotrauma Surgery, National Institute of Neurosciences \& Hospital, Dhaka, Bangladesh; ${ }^{2}$ Assistant \\ Professor, Department of Microbiology, National Institute of Neurosciences \& Hospital, Dhaka, Bangladesh; \\ ${ }^{3}$ Associate Professor, Department of Microbiology, National Institute of Neurosciences \& Hospital, Dhaka, \\ Bangladesh; ${ }^{4}$ Senior consultant (Ortho-surgery), Sadar Hospital, Cox’s Bazar, Bangladesh; ${ }^{5}$ Junior \\ Consultant, Department of Orthopedic Surgery, Mymensingh Medical College, Mymensingh, \\ Bangladesh; ${ }^{6}$ Senior Consultant, Impulse Hospital, Dhaka, Bangladesh; ${ }^{7}$ Senior Consultant, \\ Impulse Hospital, Dhaka, Bangladesh
}

[Received: 21 June 2017; Revised: 6 November 2017; Accepted: 11 December 2017; Published: 1 January 2018]

\begin{abstract}
Background: Traumatic thoraco-lumbar spine injuries occur in different ways during working. Objectives: The purpose of the present study was to find out the-demographic Characteristics and Mode of Traumatic Thoraco-Lumbar Spine Injuries. Methodology: This cross-sectional study was conducted at the National Institute of Traumatology and Orthopaedic Rehabilitation (NITOR), Dhaka, Bangladesh from July 2004 to June 2006 for a period of 2(two) years. Patients with diagnosed cases of traumatic thoraco-lumbar spinal injury with complete or incomplete cord lesion irrespective of sex were selected as study population. An elaborate history of the selected patient was taken with an emphasis of mechanism, time of injury, past history of illness. Result: A total number of 17 patients with thoracolumbar spine injury were recruited. Out of 17 patients, $7(41.2 \%)$ patients were in the age group of $21-30$ years that is very younger age group. The mean age was 29.29 years. The male and female ratio was 4.7:1. In this series most affected people are farmer $(47.05 \%)$. Most affected groups are injured by fall from height $(70.58 \%)$ especially from tree and from roof of the buildings. Conclusion: Young age group male workers are most commonly affected in traumatic thoraco-lumbar spine injuries. [Journal of National Institute of Neurosciences Bangladesh, 2018;4(1): 51-53]
\end{abstract}

Keywords: Socio-demographic characteristics; mode of injuries; traumatic; thoraco-lumbar spine

Correspondence: Dr. Md. Mizanur Rahman, Junior Consultant (Ortho-surgery), Upazila Health Complex, Gaforgaon, Mymensingh, Bangladesh; Email: mizan2121@yahoo.com; Cell no.: +8801711311321

Conflict of Interest: The authors declare that they have no competing interest.

Contributions to Authors': Rahman MM, Rahman MM involved in the protocol preparation, concept of protocol, procedure and collection of data upto report writing. Yusuf MA, Sattar AFMA, Ali MA, Rahman MM, Siddique AB had revised the manuscript. All the authors have read and approved the final version of the manuscript.

Funding: This research project was not funded by any group or any institute on.

How to cite this article: Rahman MM, Rahman MM, Yusuf MA, Sattar AFMA, Ali MA, Rahman MM, Siddique AB. Socio-demographic Characteristics and Mode of Traumatic Thoraco-Lumbar Spine Injuries at a Referral Tertiary Care Hospital in Bangladesh. J Natl Inst Neurosci Bangladesh, 2018;4(1): 51-53

Copyright: (C2018. Rahman et al. Published by Journal of National Institute of Neurosciences Bangladesh. This article is published under the Creative Commons CC BY-NC License (https://creativecommons.org/licenses/by-nc/4.0/). This license permits use, distribution and reproduction in any medium, provided the original work is properly cited, and is not used for commercial purposes.

\section{Introduction}

Thoraco-lumbar junction is particularly prone to injury because of the transition between the relatively fixed thoracic spine and relatively mobile lumbar spine ${ }^{1}$. Injury to the cord or cauda equina occurs in approximately $10-38 \%$ of adult thoracolumbar fractures and as many as $50-60 \%$ of fracture dislocation ${ }^{2}$. A high percentage of lumbosacral fractures occur in younger than 30 years and nearly $60 \%$ of patients have serious disabling deficits ${ }^{3}$.

In spinal injuries the displaced structures may damage the cord or nerve roots or both. Cervical lesion may cause quadriplegia and thoracolumbar lesion may produce paraplegia ${ }^{1}$. Fractures of the thoracolumbar junction can produce a mixture of cord and root syndromes caused by lesions of the conus medullaris and lumbar nerve roots. 
It is very important o see the socio-demographic profiles and the way of injury to the thoraco-lumbar spine for the management. Therefore, this present study was undertaken to find out the socio-demographic characteristics and mode of traumatic thoraco-lumbar spine injuries.

\section{Methodology}

This was a cross-sectional study and was undertaken at the National Institute of traumatology and Orthopaedic Rehabilitation (NITOR), Dhaka, Bangladesh from July 2004 to June 2006 for a period of 2(two) years. Patients with diagnosed cases of traumatic thoraco-lumbar spinal injury with complete or incomplete cord lesion irrespective of sex were selected as study population. Non-traumatic paraplegic patients were excluded from this study. An elaborate history of the selected patient was taken with an emphasis of mechanism, time of injury, past history of illness. This was followed by a thorough general, local, and neurological examination for proper assessment. Anterior-posterior and lateral view X-rays were taken of the respective sites and MRI of thoracolumbar region were taken for proper spinal cord injury as well as bony injury evaluation. A predesign proforma containing history and examination finding of the patient were used.

\section{Results}

A total number of 17 patients with thoracolumbar spine injury were recruited by non-random purposive sampling technique of which 12 patients were incomplete cord lesion and 5 patients were complete cord lesion. Out of 17 patients, 7(41.2\%) patients were in the age group of 21 to 30 years that is very younger age group. The lowest age incidence was 11 years and the highest was 60 years in this series. The mean age was 29.29 years (Table 1 ).

Table 1: Age distribution of Study population

\begin{tabular}{lcc}
\hline Age Group & Frequency & Percent \\
\hline Less than 20 Years & 4 & 23.5 \\
21 to 30 Years & 7 & 41.2 \\
More Than 31 Years & 6 & 35.3 \\
Total & $\mathbf{1 7}$ & $\mathbf{1 0 0 . 0}$ \\
\hline Mean \pm SD & \multicolumn{2}{c}{$29.29 \pm 17.756$} \\
Age Range & \multicolumn{2}{c}{11 to 60 years } \\
\hline
\end{tabular}

In this series out of total 17 patients, $14(82.4 \%)$ are male and $3(17.6 \%)$ are female. The male and female ratio was 4.7:1 (Table 2).
Table 2: Sex distribution of Study population

\begin{tabular}{lcc}
\hline Gender & Frequency & Percentage \\
\hline Male & 14 & 82.4 \\
Female & 3 & 17.6 \\
Total & $\mathbf{1 7}$ & $\mathbf{1 0 0 . 0}$ \\
\hline
\end{tabular}

In this series most affected people are farmer (47.05\%) and other occupation group affected less (Table 3 ).

Table 3: Distribution of patients according to occupation

\begin{tabular}{lcc}
\hline Occupation & Frequency & Percentage \\
\hline Farmer & 08 & 47.05 \\
House wife & 02 & 11.76 \\
Shop keeper & 02 & 11.76 \\
Maid servant & 01 & 5.88 \\
Service holder & 01 & 5.88 \\
Teacher & 01 & 5.88 \\
Driver & 01 & 5.88 \\
Weight Bearer & 01 & 5.88 \\
Total & $\mathbf{1 7}$ & $\mathbf{1 0 0 . 0}$ \\
\hline
\end{tabular}

Most affected groups are injured by fall from height (70.58\%) especially from coconut tree and from roof of the buildings, all are accidental fall but those two females had a history of suicidal fall from top of the roof (Table 4).

Table 4: Distribution of Patients According To Mode of Injury

\begin{tabular}{lcc}
\hline Mode of Injury & Frequency & Percentage \\
\hline Fall from height & 12 & 70.58 \\
a) Fall from tree & 6 & 35.29 \\
b) Fall from roof of building & 6 & 35.29 \\
Direct Trauma RTA and others & & 11.76 \\
Fall of heavy object over back & 3 & 17.64 \\
Total & $\mathbf{1 7}$ & $\mathbf{1 0 0 . 0}$ \\
\hline
\end{tabular}

\section{Discussion}

Thoraco-lumbar junction is most common area of injury to the axial skeleton ${ }^{4}$. The reason of this is due to more mobile of lumber than immobile thoracic segment ${ }^{5}$. Thoraco-lumbar junction trauma often associated with neurological dysfunction. It is most often results from fall from height, automobile trauma. Vertebral column has two distinct functions that become compromised in the injured person and that must be considered in the diagnosis and treatment of each case. The first function is to house and protect the spinal cord itself second important function of the vertebral column is the structural support offered as a part of the axial skeleton ${ }^{6}$. 
The present study was undertaken at National Institute of Traumatology and Orthopaedic Rehabilitation (NTTOR), Dhaka. This is a study of evaluation of results of Tratunatic Thoraco-lumbar injury through posterior approach. In this study most of the patient felt under 21-30 years age group $41.2 \%$, while the next common age group the 31 to 40 years age group $29.4 \%$. The mean age incidence was 29.29 years. Jesse at $\mathrm{el}^{7}$ stated mean age group 29 years range ( 8 to 63 years). High incidence of young adult in the present series is due to higher rate of mobility as well as working group peoples.

Male population in this study constitutes $82.35 \%$ while females made up the remaining $17.64 \%$. According to series of Chetan at $\mathrm{el}^{5}$ male are four times higher risk than female and his series contain incidence male $(80 \%)$ and female $(20 \%)$. Male representation in many series is in majority. Males being the major working force of our society are thus more consistently exposed to the external environment, which probably accounts for this predominance. According to series of Chetan at $\mathrm{el}^{5}$, male is four-time higher risk than female and his series contain incidence male $280 \%$ and female $20 \%$. In present series most involved occupational group is farmer $(47.05 \%)$, while next common group is housewife and shopkeeper $(11.76 \%)$. Farmers are occupationally vulnerable group in contest of Bangladesh as they are active workers and by analyzing the mode of injury it is also cleared that fall from height especially from coconut trees are the main cause of injury in this occupation group.

Fall from the height $(70.58 \%)$ is the most common mode of Thoraco-Lumbar injury in this country; interestingly half of those falls from coconut trees; other half of those fall from top of buildings. Next common group of involved mode of injury is fall of heavy object over back during working (17.64\%). In series of Jesse at $\mathrm{el}^{7}$ it has been found that the common mode is road traffic accident (48.44\%) and among those study population automobile accident is $26.05 \%$ and motorcycle accident is $22.44 \%$ cases. Next common mode of injury is fall $(30.61 \%)$. The mode of injury in Thoraco-Lumbar spine in between two series is due to socioeconomically status difference between two places of study. In Bangladesh fall from height is the prime group in contrast to that in America where Jesse at $\mathrm{el}^{7}$ study has done are more porn to road traffic accident.

\section{Conclusion}

In conclusion the most common age group is younger age group. Furthermore, male gender are predominant than female. Most commonly farmers were affected. Fall from height was the commonest cause of thoraco-lumber injuries followed by injury due to fall of heavy object over back.

\section{References}

1. Solomon L, Wamck D, Selvaduria N. Apley's systems of Orthopedics and fractures, Neural injuries, 5th edi, 662- 665

2. Crawford AJ, Hamblen D. Outline of the fracture, Spine and thorax, 11th edi. Churchill Livingstone, Edinburgh- London, 1999, 99-110

3. Federico CV. Lumbar spine fracture and dislocation, Spine, 2004;21:1-11

4. Chummy SS. Last's anatomy Regional and applied Spinal cord, 10th edi. Churchill Livingstone, Edinburgh-London, 1999;445-486

5. Chetan KP, Eeric T, Jeffrey SF, Henry NH. Evaluation and Treatment of thoracolumber Junction Trauma. UPOJ Journal, 2002; $15: 7-12$

6. Smith G, Walter MC. Fracture \& Dislocation of the Spine, Chap 1998;19:1805-1816.

7. Jesse HD, Paul HR, Wendell DE. Results of Reduction and Stabilization of the Severely Fractured Thoracic and Lumber spine, Journal ofloints and Bone Surgery 1978;60(6):799-805 